\title{
Truncus arteriosus communis with intact ventricular septum
}

Sir,

We read with attention the paper by Carr et al. entitled "Truncus arteriosus communis with intact ventricular septum". ${ }^{1}$ The authors document clinically and pathologically a patient with truncus arteriosus communis in which the ventricular outflow tracts were completely separate below a common semilunar valve. The case furnishes evidence that the presence of an infundibular septal defect is not essential in defining truncus arteriosus communis, and otherwise suggests that the septation of the cardiac outflow tracts comes from distinct development of conal, truncal, and aortopulmonary septa.

These concepts had been clearly underlined in our recent paper. ${ }^{2}$ The spectrum of malformations illustrated by Carr et al. ${ }^{1}$ in their Fig. 6 corresponds to the one schematically anticipated by us. Indeed, the case reported by these authors had been foreseen in Fig. 11 of our paper as "absent truncal and aortopulmonary septa with normally developed conal septum (not described so far)".

We regret that our contribution, though published in the British Heart fournal, ${ }^{2}$ has not been quoted. Using Dr Bharati's own words ${ }^{3}$ we would suggest, "to read the literature carefully and include the previous work done by other people. This may perhaps help to write a paper in an objective manner".

Gaetano Thiene, Uberto Bortolotti, Department of Pathology and Cardiovascular Surgery, University of Padova Medical School, Padova, Italy.

\section{References}

${ }^{1}$ Carr I, Bharati S, Kusnoor VS, Lev M. Truncus arteriosus communis with intact ventricular septum. Br Heart f 1979; 42: 97-102.

${ }^{2}$ Thiene G, Bortolotti U, Gallucci V, Terribile V, Pellegrino PA. Anatomical study of truncus arteriosus communis with embryological and surgical considerations. Br Heart $\mathcal{F}$ 1976; 38: 1109-23.

${ }^{3}$ Bharati S. TAPVC: vital statistics (letter). Am Heart $\mathcal{f}$ 1976; 92: 410.
This letter was shown to Dr Carr and his colleagues who reply as follows:

We have long enjoyed the contributions to the journals made by Drs Thiene and Bortolotti and look forward to doing so in the future. We are unable to share their wish that we had quoted them in our paper and we do not agree with the three reasons for doing so that they have given. Like ourselves, Thiene et al. cannot claim originality for any of the concepts common to both papers. Every malformation contained in the spectrum illustrated in our paper had been described by other authors, not only previous to our own paper, but also previous to the paper by Thiene et al. (which described a theoretical spectrum, not restricted to hearts that had already been described). Finally, the idea of truncus arteriosus without ventricular septal defect is not a new one, for example. ${ }^{1}$ Cases such as ours had been reported by other authors before Thiene et al. restated the possibility of their existence. These facts are clear from the references we cited.

Translating into the terminology used by Thiene et al., our paper corroborates the concepts ${ }^{2}$ that absence of septation of the ventricular infundibulum is not invariable, that not all types of truncus arteriosus should be considered as a single undivided conotruncus, and that the only necessary condition for the diagnosis of truncus arteriosus is a single semilunar valve common to both ventricles (and we should add, common to both great arteries). Thiene et al. reached the opposite conclusion; we quote from their Summary: "The invariable absence of septation of the ventricular infundibulum and semilunar valve, in spite of the variable anatomy of the free wall of the conus, indicates that all types of truncus arteriosus, ontogenetically, should be considered as a single undivided conotruncus" (emphasis added).

Our paper described a single heart, not the first of its kind to be reported, but the first of its kind on which there was so much information. We showed how this heart corroborated concepts expressed by previous authors. Had we, instead, 
written an exhaustive review of the subject we would then have included the citation of their paper.

Ian Carr, Saroja Bharati, Maurice Lev, Division of Pediatric Cardiology, Cook County Hospital and Congenital Heart Disease Research and Training Center, Hektoen Institute for Medical Research, Chicago, Illinois, USA.

\section{References}

${ }^{1}$ Collett RW, Edwards JE. Persistent truncus arteriosus: a classification according to anatomic types. Surg Clin North Am 1949; 29: 1245-70.

${ }^{2}$ Van Mierop LHS, Patterson DF, Schnarr WR. Pathogenesis of persistent truncus arteriosus. Am $\mathcal{f}$ Cardiol 1978; 41 : 755-62. 